\title{
Corrosion Inhibition of Carbon Steel in Acidic Environment by Papaya Seed as Green Inhibitor
}

\author{
Subir Paul $^{1}$ - Ishita Koley ${ }^{1}$
}

Received: 20 November 2015/Revised: 3 February 2016/Accepted: 5 February 2016/Published online: 21 March 2016

(C) Springer International Publishing Switzerland 2016

\begin{abstract}
Chemicals used presently for corrosion inhibitors in Industries are highly toxic to both human beings and environment. These inhibitors may cause the damage to organ system viz., kidneys or liver, or to disturb a biochemical process of an enzyme system at some site in the body. For papaya seed, a vegetable waste is found to act as a very good green inhibitor, in preventing acid corrosion of low-carbon construction steel. The study was made in 0.5 to $3 \mathrm{~N} \mathrm{H}_{2} \mathrm{SO}_{4}$ with the variation of concentration. An increase in inhibitor concentration decreases the rate of degradation. But there is an optimum concentration at which the inhibitor effect is maximum, beyond that the corrosion rate again increases. The adsorption study shows that the mechanism of corrosion inhibitor is due to physical adsorption, following Temkin adsorption isotherms. Electrochemical impedance spectroscopy study showed that the corrosion inhibition by the papaya seed is due to an increase in polarization resistance and impedance at metalsolution interface.
\end{abstract}

Keywords Green inhibitor · Papaya seed · Acid corrosion · Adsorption isotherm

Subir Paul

spaul@metal.jdvu.ac.in

Ishita Koley

koley3@gmail.com

1 Department of Metallurgical and Material Engineering, Jadavpur University, Kolkata, India

\section{Introduction}

Acid corrosion of carbon steel articles is inhibited by synthetic organic inhibitors like phenylthiourea, pyridine, and quinoline. A number of heterocyclic compounds with $\mathrm{N}, \mathrm{S}$, and $\mathrm{O}$ as hetero atoms are proved to be effective corrosion inhibitors $[1,2]$, and the screening of synthetic heterocyclic compounds is still being continued. Although many synthetic compounds showed good anticorrosive activities, most of them are highly toxic to both human beings and environment. The safety and environmental issues of corrosion inhibitors in industries have always been a global concern. These inhibitors may cause the reversible (temporary) or irreversible (permanent) damage to organ system like, kidneys, liver, or to disturb a biochemical process of an enzyme system at some site in the body. The toxicity may manifest either during the synthesis of the compound or during its applications. These toxic effects have led to the use of natural products as anticorrosion agents which are eco-friendly and harmless [3]. In recent days, many alternative ecofriendly corrosion inhibitors have been developed, and they range from rare earth elements [4] to organic compounds [5-8]. A few natural products such as plant extracts and animal proteins were reported [9] to have been used in pickling acid bath. In the previous investigation by the author [10], corrosion inhibition of carbon steel by few green inhibitors viz. garlic, yeast, pepper, and coffee is studied. These green inhibitors have been found to decrease the acid corrosion of mild steel by several folds with about $70-90 \%$ adsorption on the surface. Watermelon extract has been found [11] to have strong effect on corrosion of mild steel in $\mathrm{HCl}$ and $\mathrm{H}_{2} \mathrm{SO}_{4}$. The inhibition efficiency increases with the concentration of the extract increases. 
In the present investigation, papaya seed extract has been used to inhibit the degradation of low-carbon steel in sulfuric acid solution to investigate how naturally produced plant waste electrochemically behave in combating acid corrosion of steel on mild steel. The mechanism of corrosion inhibition is also carried out by studying different adsorption models. The present objective of the study is to minimize the degradation of steel parts in contact with acid $\left(\mathrm{H}^{+}\right.$ions) by a naturally occurring vegetable product which does not harm any environment, including any biological system. $\mathrm{H}^{+}$ions are there in body fluids and also generated in the digestive system in human and animals. Metallic implants in contact with $\mathrm{H}^{+}$ions are prone to degradation. Although low-carbon steel is not used as implant material, coated carbon steel is investigated [12] as low cost implant material.

\section{Experimental Methods}

The test specimens were mild steel $(\mathrm{C}=0.24 \%$, $\mathrm{Mn}=0.72 \%, \mathrm{Si}=0.51 \%, \mathrm{~S}=0.049 \%$, and $\mathrm{P}=0.51 \%$ ) of size $24 \times 5 \mathrm{~mm}$. They were polished against a series of emery papers up to $3 / 0$ grade and subsequently cloth polished. The sample was cleaned with acetone before each polarization test.

\subsection{Solution Preparation}

Electrochemical polarization studies of the above test specimens were conducted in $0.5 \mathrm{M} \mathrm{H}_{2} \mathrm{SO}_{4}, 1 \mathrm{M} \mathrm{H}_{2} \mathrm{SO}_{4}$, and $3 \mathrm{M}$ $\mathrm{H}_{2} \mathrm{SO}_{4}$ (at $25^{\circ} \mathrm{C}$ ) prepared in double distilled deionized water, with or without different concentration of the inhibitor.

\subsection{Inhibitor Preparation}

Papaya seed (see Fig. 1) extract was made by grinding $25 \mathrm{~g}$ of papaya seeds and boiling them in $100 \mathrm{cc}$ of $5 \mathrm{M} \mathrm{H}_{2} \mathrm{SO}_{4}$ solution for $15 \mathrm{~min}$. The solution was reduced to less than $50 \mathrm{cc}$ by boiling. The solution was filtered. $10 \mathrm{cc}$ of the solution was preserved for inhibitor. The inhibitor concentration in the experiments were varied from 200 to $1500 \mathrm{ppm}$ and added in $0.5 \mathrm{M} \mathrm{H}_{2} \mathrm{SO}_{4}, 1 \mathrm{M} \mathrm{H}_{2} \mathrm{SO}_{4}$, and $3 \mathrm{M} \mathrm{H}_{2} \mathrm{SO}_{4}$ acid solutions. The main chemical constituent of the papaya seed seems to be benzyl iso thiocyanate which is responsible for corrosion mitigation[13]; the organic structure of it is also shown in Fig. 1.

\subsection{Electrochemical Polarization Study}

Standard three electrodes corrosion cell (saturated calomel electrode as reference electrode, graphite rod as counter electrode, and the steel sample as working electrode) was used to perform the electrochemical potentiodynamic polarization tests of the above steel specimens in acid solution with or without the inhibitor. Polarization experiments were carried out as per ASTM standard methods (ASTM G5: Potentiostatic and Potentiodynamic Polarization Measurements and ASTM G 59: Polarization Resistance Measurements) with a scan rate of $1 \mathrm{mV} / \mathrm{sec}$, using computer controlled Gamry Potentiostat. Each of the experiments was repeated thrice to verify the consistency of the experimental data. Corrosion rates $\left(i_{\text {corr }}\right)$ were determined from the polarization plots of experimental data by Tafel's extrapolation method.

\subsection{Electrochemical Impedance Spectroscopy (EIS)}

For EIS study, the experimental arrangement was same as that of polarization studies. The electrochemical cell was connected to an impedance analyzer (EIS300 controlled by Echem analyst software) for electrochemical impedance spectroscopy. The electrochemical impedance spectra were obtained at frequencies between $100 \mathrm{kHz}$ and $0.1 \mathrm{~Hz}$. The following results and information were obtained from the EIS experiments: polarization resistance $\left(R_{\mathrm{p}}\right)$, electrolyte resistance $(\mathrm{Ru})$, double layer capacitance $\left(C_{\mathrm{dl}}\right)$, capacitive

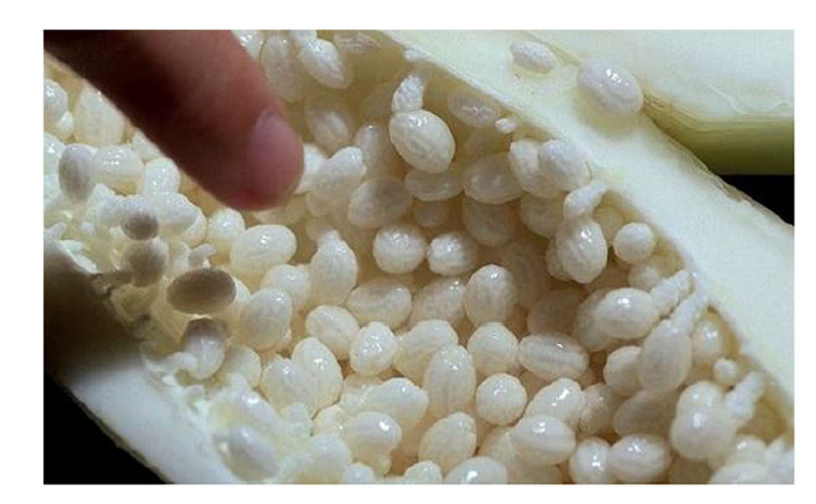

Papaya seed used for experiment

Fig. 1 Image of papaya seeds used for making the inhibitor extract and main organic constituent papaya seed supposed to be acting as inhibitor 
load or constant phase element, CPE (Y), and $\alpha$ which is defined from the capacitive impedance equation $Z=1 / C(\mathrm{jw})^{-\alpha}$. Capacitors in EIS experiments often do not behave ideally. Instead, they act like a constant phase element (CPE). The exponent $\alpha$ is 1 for ideal capacitance. For a constant phase element, the exponent $\alpha$, is less than one.

\subsection{Adsorption Study}

The fraction of inhibitor adsorbed $\theta$ was determined from the following equation.

$\theta=\left(1-i_{\text {In_corr }} / i_{\text {corr }}\right)$,

where $i_{\text {In_corr }}$ and $i_{\text {corr }}$ are the corrosion current density with and without inhibitor, respectively.

\section{Results and Discussion}

The effect of the inhibitor on the corrosion rate of the steel in $0.5 \mathrm{M} \mathrm{H}_{2} \mathrm{SO}_{4}$ is shown in Fig. 2. It is seen that the inhibitor reduces the corrosion rate and the degree of reduction increases with increase in concentration, with an optimum inhibitor concentration of $1500 \mathrm{ppm}$, when the effect is maximum. The corrosion potential does not change much, indicating it is a mixed inhibitor. Figure 3 shows similar polarization curves in $1 \mathrm{~N} \mathrm{H}_{2} \mathrm{SO}_{4}$ solution. It is seen here that the effect of the inhibitor is much more in mitigation of corrosion of carbon steel and an increase in the inhibitor concentration decreases the corrosion rate to much lower value. Similar study in $3 \mathrm{~N}$ acid solution with and without the inhibitor is shown in Fig. 4. It is seen here that the rate of corrosion decreases with increasing the inhibitor concentration up to a certain limit, beyond that concentration, the corrosion rate again increases. It seems that at high inhibitor concentration beyond a limit, the inhibitor substance can no more gets adsorbed on the metal substrate, rather dissolves in acid solution and increases the acid concentration.

From the foregoing graphs, it is confirmed that the papaya seed acts as a very powerful inhibition for steel corrosion, and the effect of this green inhibitor is more in higher concentration acid. Figure 5 displays comparison of fraction of the inhibitor absorbed on metal surface in $0.5,1$, $3 \mathrm{~N} \mathrm{H}_{2} \mathrm{SO}_{4}$ solution with different concentration of inhibitor. It is seen that the percentage of inhibitor adsorbed on the metal surface increases with inhibitor concentration, reaching a maxima (where the corrosion rate of the steel is minima), after which the adsorption of inhibitor falls. This trend is there for all the curves, indicating there is a critical concentration of the inhibitor for a fixed acid concentration, when the inhibitor adsorption is maximum and the corrosion rate is minimum. It is also to be noted that the efficiency of the inhibitor is maximum in higher concentrated acid, compared to that in lower concentration acid. It is seen in Fig. 1 that the structure of Benzyliso thiocyanate (a constituent responsible for inhibition in papaya seed) is having two doubly bonded carbon, sharing with $\mathrm{N}$ and $\mathrm{S}$. The presence of excess $\mathrm{H}^{+}$helps to break the double bonded arm which opens up, forming a coordinate bond with the metal substrate and thereby adsorption of the
Fig. 2 Polarization diagram of mild steel in $0.5 \mathrm{M} \mathrm{H}_{2} \mathrm{SO}_{4}$ with papaya seed as inhibitor

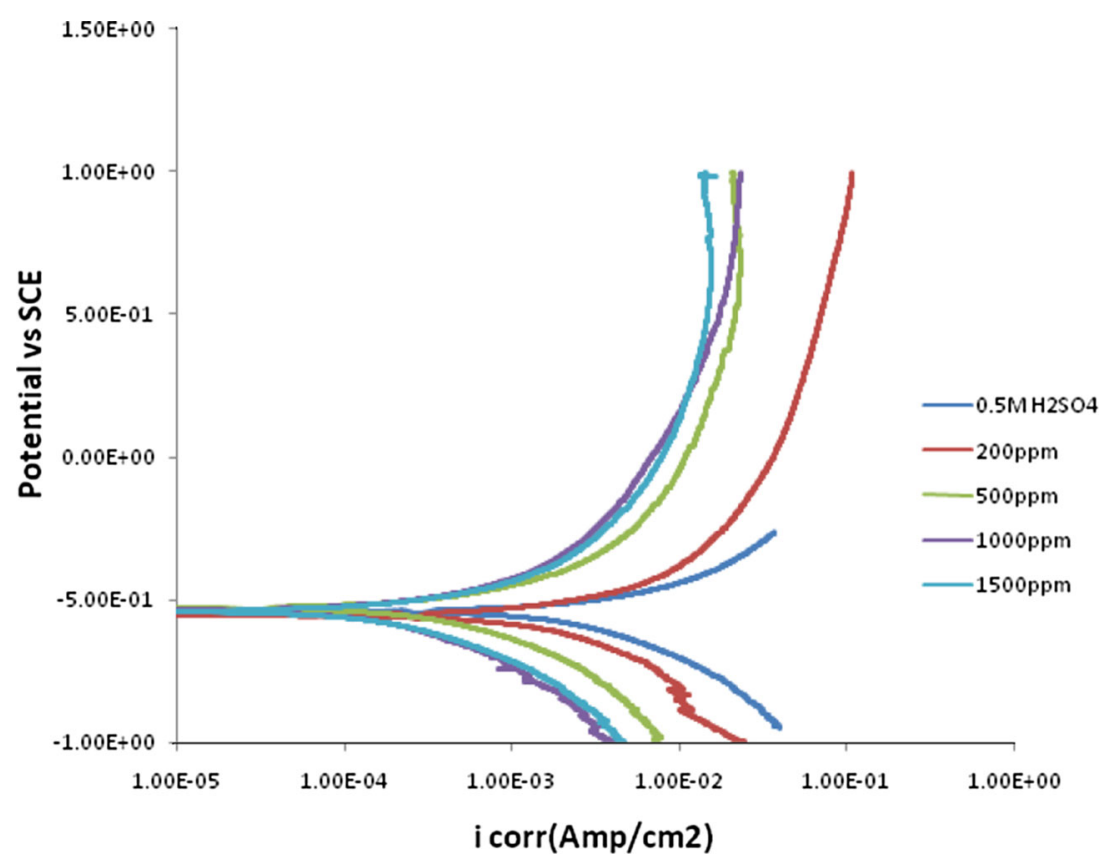


Fig. 3 Polarization diagram of mild steel in $1 \mathrm{M} \mathrm{H}_{2} \mathrm{SO}_{4}$ with papaya seed as inhibitor
Fig. 4 Polarization diagram of mild steel in $3 \mathrm{M} \mathrm{H}_{2} \mathrm{SO}_{4}$ with papaya seed as inhibitor
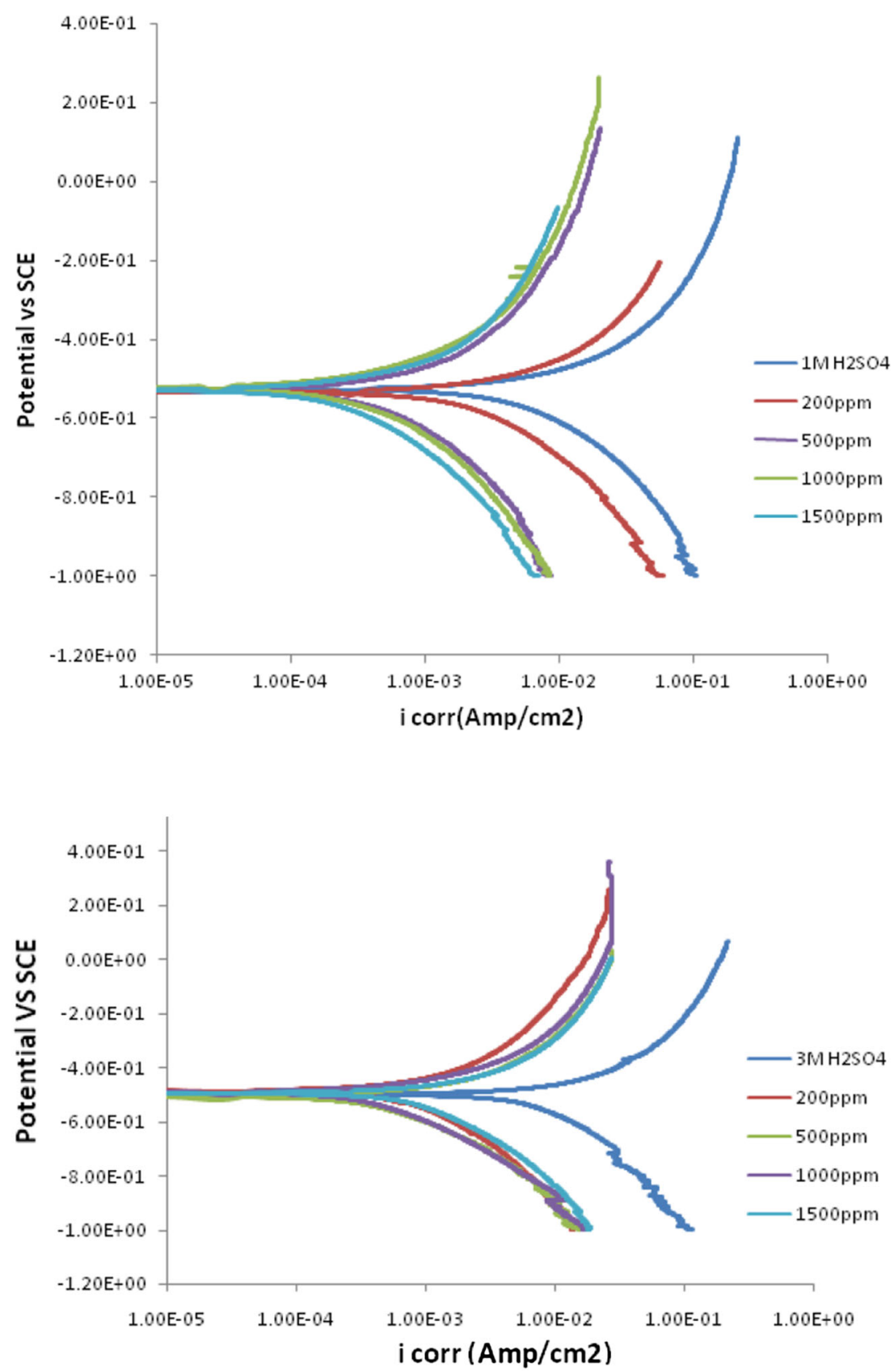

inhibitor takes place, reducing the rate of corrosion. Thus the corrosion rate of carbon steel can be minimized by the papaya seed inhibitor irrespective of any acid concentration, at higher concentration of the inhibitor.

\subsection{Adsorption Study}

Adsorption isotherms [14] are very important in understanding the mechanism of inhibition of corrosion reaction. The most frequently used adsorption isotherms are Frumkin, Temkin, Freundlich, and Langmuir isotherms. Deter- mination of adsorption isotherm equation that best fit the adsorption data helps to compute free energy of adsorption from the following equation.

$\Delta G_{\text {ads }}=-2.303 \mathrm{RT} \log \left(55.5 K_{\mathrm{ads}}\right)$,

where $K_{\text {ads }}$ is the adsorption equilibrium constant. The constant 55.5 is the molar concentration of water in the solution. If the calculated values of $\Delta G_{\text {ads }}$ are negative and less than the threshold value of $-40 \mathrm{~kJ} / \mathrm{mol}$, it confirms that the adsorption of inhibitors on mild steel is spontaneous and that physical adsorption mechanism is applicable. 
Fig. 5 Fraction of metal surface adsorbed by the inhibitor with increase in inhibitor concentration in $\mathrm{H}_{2} \mathrm{SO}_{4}$ solution

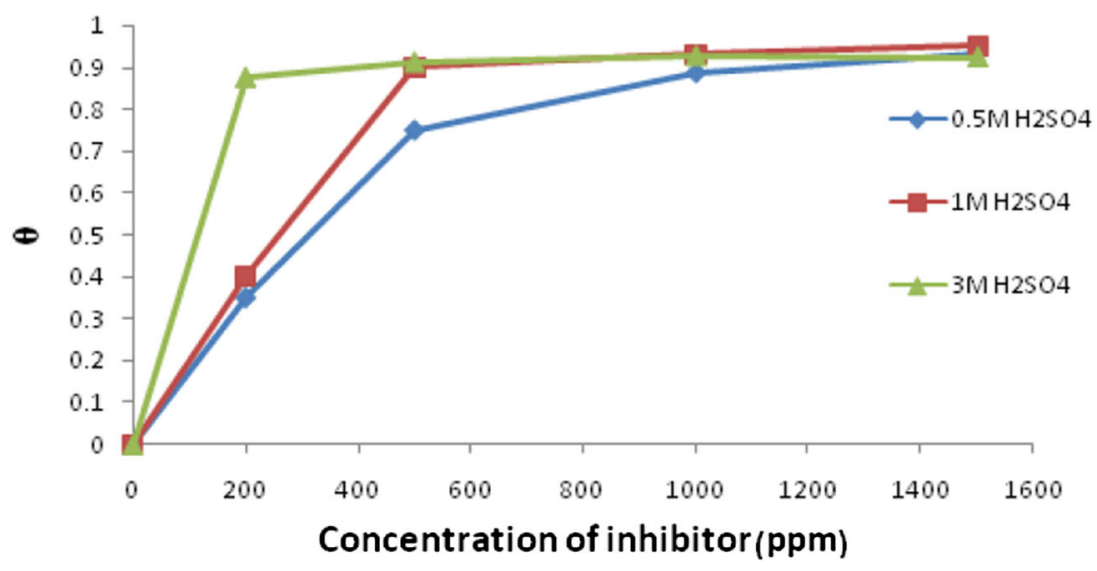

Fig. 6 Temkin adsorption isotherm in different concentration of $\mathrm{H}_{2} \mathrm{SO}_{4}$ solution with the inhibitor

\subsection{Langmuir Adsorption Isotherm}

The Langmuir isotherm is the first choice for most models of adsorption and has many applications in surface kinetics. Langmuir adsorption is valid for low coverage. It is based on four assumptions:

1. The surface of the adsorbent is uniform, that is, all the adsorption sites are equivalent.

2. Adsorbed molecules do not interact.

3. All adsorption occurs through the same mechanism.

4. At the maximum adsorption, only a monolayer is formed: molecules of adsorbate do not deposit on other, already adsorbed, molecules of adsorbate, but only on the free surface of the adsorbent.

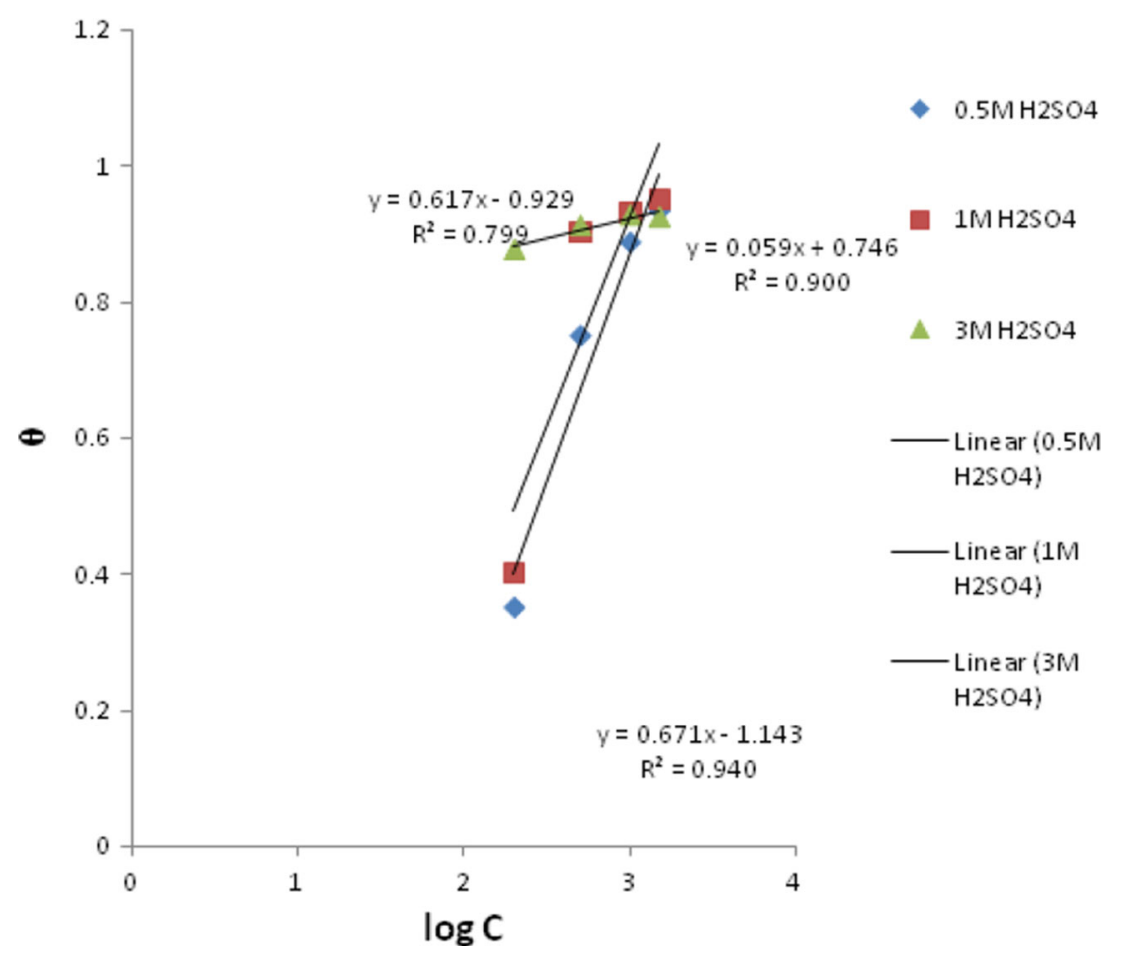

The equation $\theta /(1-\theta)=\mathrm{KC}$ So $\log [\theta /(1-\theta)]=$ $\log \mathrm{c}+\log \mathrm{K}$ plotting $\log [\theta /(1-\theta)]$ versus $\log \mathrm{c}$, intercept gives $\log \mathrm{K}$;

\subsection{Temkin Adsorption Isotherm}

Temkin adsorption isotherm is only valid and effective at $0.2<\theta<0.8$. It assumes molecular interaction between adsorbed molecules. The equation is as follows:

$\mathrm{KC}=e^{\mathrm{f} \theta}, \ln \mathrm{K}+\ln \mathrm{C}=\mathrm{f} \theta$,

where $\mathrm{f}$ is a molecular interaction parameter related to the molecular interactions in the adsorption layer as well as energetic inhomogeneity of the surface, and $\mathrm{C}$ is the 
Fig. 7 Frumkin adsorption isotherm in different concentration of $\mathrm{H}_{2} \mathrm{SO}_{4}$ solution with the inhibitor

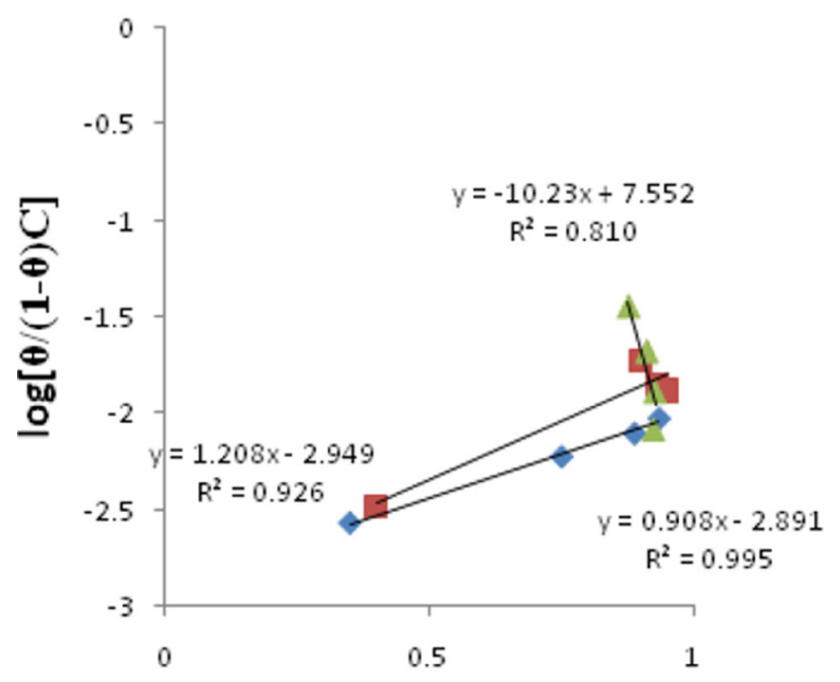

$0.5 \mathrm{MH} 2 \mathrm{SO} 4$

$1 \mathrm{MH} 2 \mathrm{SO} 4$

A $3 \mathrm{MH} 2 \mathrm{SO} 4$

Line ar $10.5 \mathrm{M}$ $\mathrm{H} 2 \mathrm{SO}$ )

- Line ar ( $1 \mathrm{M}$ $\mathrm{H} 2 \mathrm{SO} 4)$

- Line ar $(3 \mathrm{M}$ $\mathrm{H} 2 \mathrm{SO} 4)$
Fig. 8 Langmuir adsorption isotherm in different concentration of $\mathrm{H}_{2} \mathrm{SO}_{4}$ solution with the inhibitor

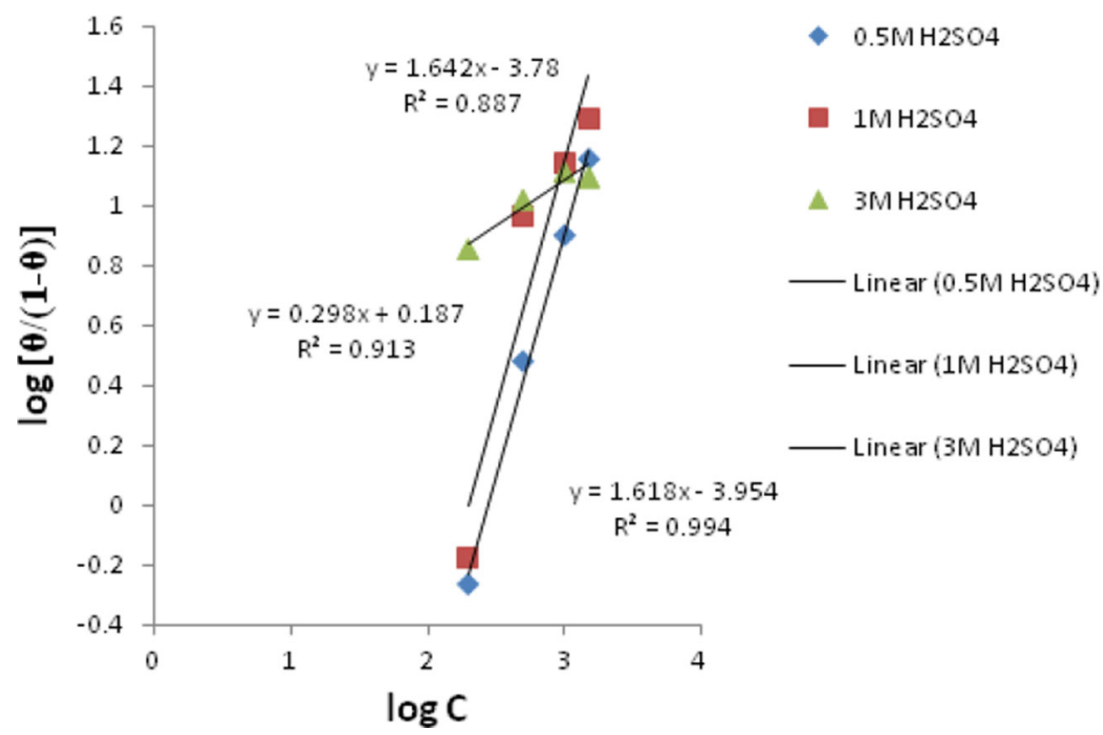

concentration in mole. So $\log \mathrm{C}=\mathrm{f} \theta / 2.303-\log \mathrm{K}$, plotting $\log \mathrm{C}$ versus $\theta$, intercept $=-\log \mathrm{K}$.

\subsection{Frumkin Adsorption Isotherm}

The Frumkin adsorption isotherm assumes that the electrode surface is inhomogeneous or that the lateral interaction effect is not negligible. The equation is as follows:

$\theta /(1-\theta)=\mathrm{Kce}^{2 \mathrm{a} \theta}$,

$\ln [\theta /(1-\theta) \mathrm{c}]=\ln \mathrm{K}+2 \mathrm{a} \theta$,

where $a$ is an interaction parameter, taking into account, the attraction $(a>0)$ or repulsion $(a<0)$ between the adsorbed species. For $a=0$ (no interaction), this isotherm becomes equivalent to the Langmuir isotherm. For $+v e$ a, adsorption energy decreases with $\theta$ whereas for negative a, adsorption energy decreases with $\theta$.Plotting, $\ln [\theta /(1-\theta) \mathrm{c}]$ versus $\theta$, intercept gives $\ln \mathrm{K}$.

Figure 6 illustrates the Temkin isotherm mechanism for this green inhibitor. Figure 7 shows the Frumkin adsorption characteristics of three different acid solutions with different concentration of inhibitor. Figure 8 describes the Langmuir isotherm adsorption for $0.5 \mathrm{~N} \mathrm{H}_{2} \mathrm{SO}_{4}, 1 \mathrm{~N}$ $\mathrm{H}_{2} \mathrm{SO}_{4}$, and $3 \mathrm{~N} \mathrm{H}_{2} \mathrm{SO}_{4}$.

The adsorption data have been made to fit into the models of Temkin, Langmuir, and Frumkin adsorption isotherms as shown, respectively in Figs, 6, 7, and 8 with regression coefficient and equations given in figures. 
Table 1 Adsorption isotherm with different $\mathrm{H}_{2} \mathrm{SO}_{4}$ solution with papaya seed inhibitor

\begin{tabular}{|c|c|c|c|c|c|c|c|c|c|}
\hline & \multicolumn{3}{|l|}{ Temkin } & \multicolumn{3}{|l|}{ Langmuir } & \multicolumn{3}{|l|}{ Frumkin } \\
\hline & Reg. coefficient & $\mathrm{K}$ & $\Delta \mathrm{G} \mathrm{Kj} / \mathrm{m}$ & Reg. coefficient & $\mathrm{K}$ & $\Delta \mathrm{G} \mathrm{Kj} / \mathrm{m}$ & Reg. coefficient & $\mathrm{K}$ & $\Delta \mathrm{G} \mathrm{Kj} / \mathrm{m}$ \\
\hline $0.5 \mathrm{M} \mathrm{H}_{2} \mathrm{SO}_{4}$ & 0.9407 & 13.92 & -16.5 & 0.9944 & 9001 & -32.515 & 0.9952 & 18.01 & -17.11 \\
\hline $1 \mathrm{M} \mathrm{H}_{2} \mathrm{SO}_{4}$ & 0.7997 & 8.5 & -15.25 & 0.8878 & 6025 & -31.52 & 0.926 & 19.08 & -17.26 \\
\hline $3 \mathrm{M} \mathrm{H}_{2} \mathrm{SO}_{4}$ & 0.9001 & 5.57 & -14.3 & 0.9135 & 74.47 & -20.63 & 0.8105 & 1906 & -28.66 \\
\hline
\end{tabular}

Table 2 Values of EIS parameter for $1 \mathrm{M} \mathrm{H}_{2} \mathrm{SO}_{4}$ with or without inhibitor

\begin{tabular}{lll}
\hline Parameter & Values for $1 \mathrm{~N} \mathrm{H}_{2} \mathrm{SO}_{4}$ & Values for $1 \mathrm{~N} \mathrm{H}_{2} \mathrm{SO}_{4}$ with inhibitor \\
\hline$Y_{\mathrm{o}}$ ohms & 55,700 & 234 \\
Alpha & 0.63 & 0.88 \\
$R_{\mathrm{p}}(\mathrm{ohm})$ & 437 & 135,000 \\
\hline
\end{tabular}
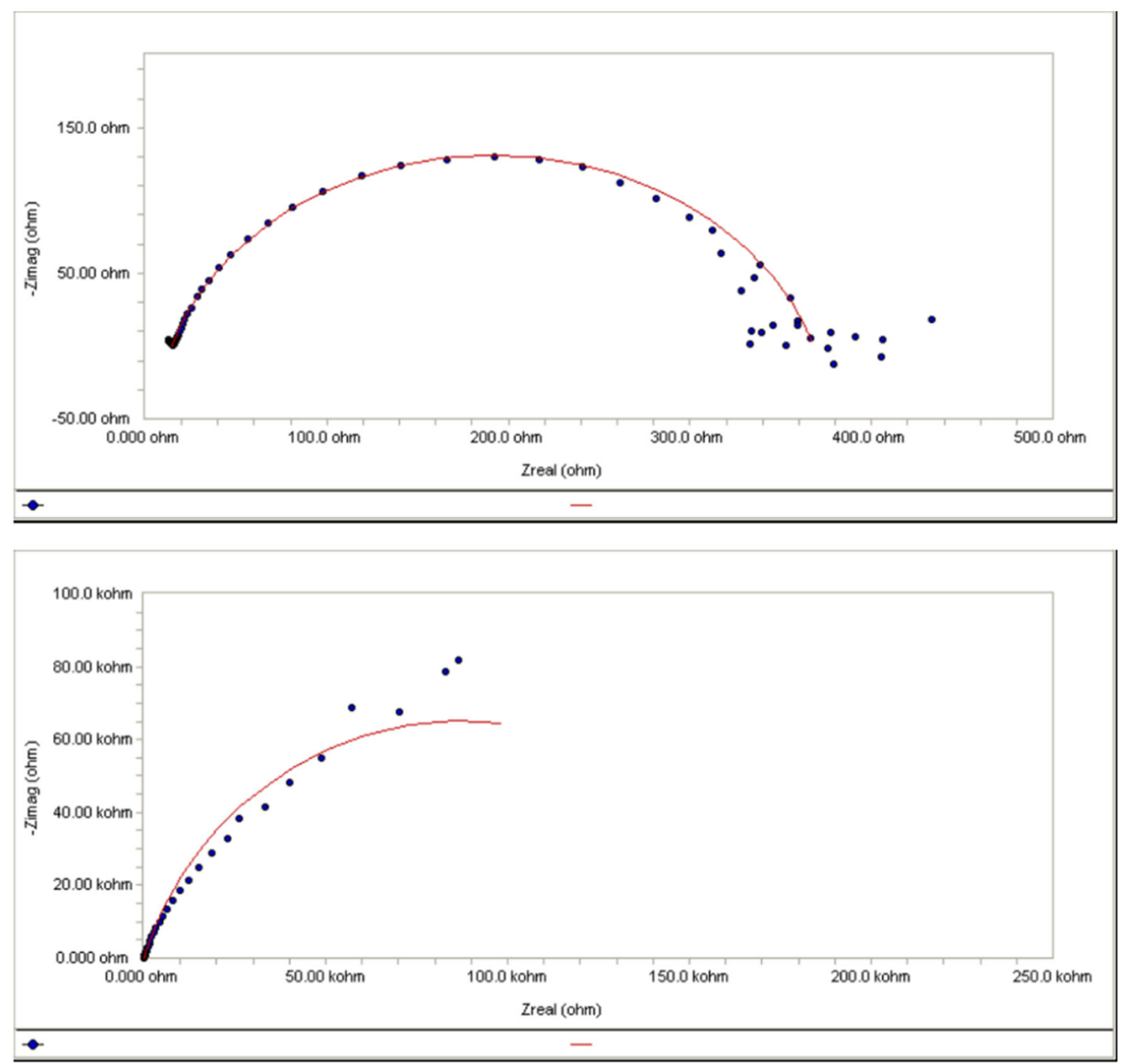

Fig. 9 Nyquist plot in $1 \mathrm{M} \mathrm{H}_{2} \mathrm{SO}_{4}$ without the inhibitor (top) and with inhibitor (bottom) 
Table 1 compares regression coefficients of the adsorption data fitting into three models. The model with regression coefficient less than 0.8 has been rejected as unfit. It is seen in $0.5 \mathrm{~N} \mathrm{H}_{2} \mathrm{SO}_{4}$ solution, the inhibitor adsorption data best fit in all three models, with heat of adsorption between 16 and $32 \mathrm{kj} / \mathrm{m}$. The values are negative, which signifies that it is a spontaneous reaction, and the value is less than $40 \mathrm{kj} /$ $\mathrm{m}$, so it is not chemisorption but physical adsorption. The regression results in Table 1 do not give a very clear idea about the best fit adsorption isotherm. In $1 \mathrm{~N} \mathrm{H}_{2} \mathrm{SO}_{4}$ solution, the regression coefficient with the Frumkin model (heat of adsorption $17 \mathrm{kj} / \mathrm{m}$ ) is little more than those in other models. And in $3 \mathrm{NHCl}$ solution, Temkin and Langmuir models show a better regression values than the other one. But that does not confirm any trend. One needs to consider other factors such as range of valid $\theta$ values and maximum adsorption for each isotherm.
Langmuir adsorption is valid for low coverage, based on assumptions: the adsorbent is uniform and adsorbed molecules do not interact. It is seen in Fig. 5 that in $3 \mathrm{~N} \mathrm{H}_{2} \mathrm{SO}_{4}$ solution, the maximum adsorption of the inhibitor on the metal surface is close to $90 \%$, coverage. In lower concentration acid, initially $\theta$ value is less (Fig. 5) but with increase in inhibitor concentration the metal surface coverage goes close to $90 \%$. So Langmuir adsorption model is rejected, irrespective of any acid concentration and so the Temkin model best fits. It is based on multilayer adsorption with lateral interaction. Temkin adsorption isotherm is effective at $0.2<\theta<0.9$. It is seen the $\theta$ value has started from low coverage and has gone up close to 0.9 (Temkin) (Fig. 5). Temkin model assumes molecular interaction between adsorbed molecules. So the results support the model.

The free energy of adsorption is computed from the following equation:
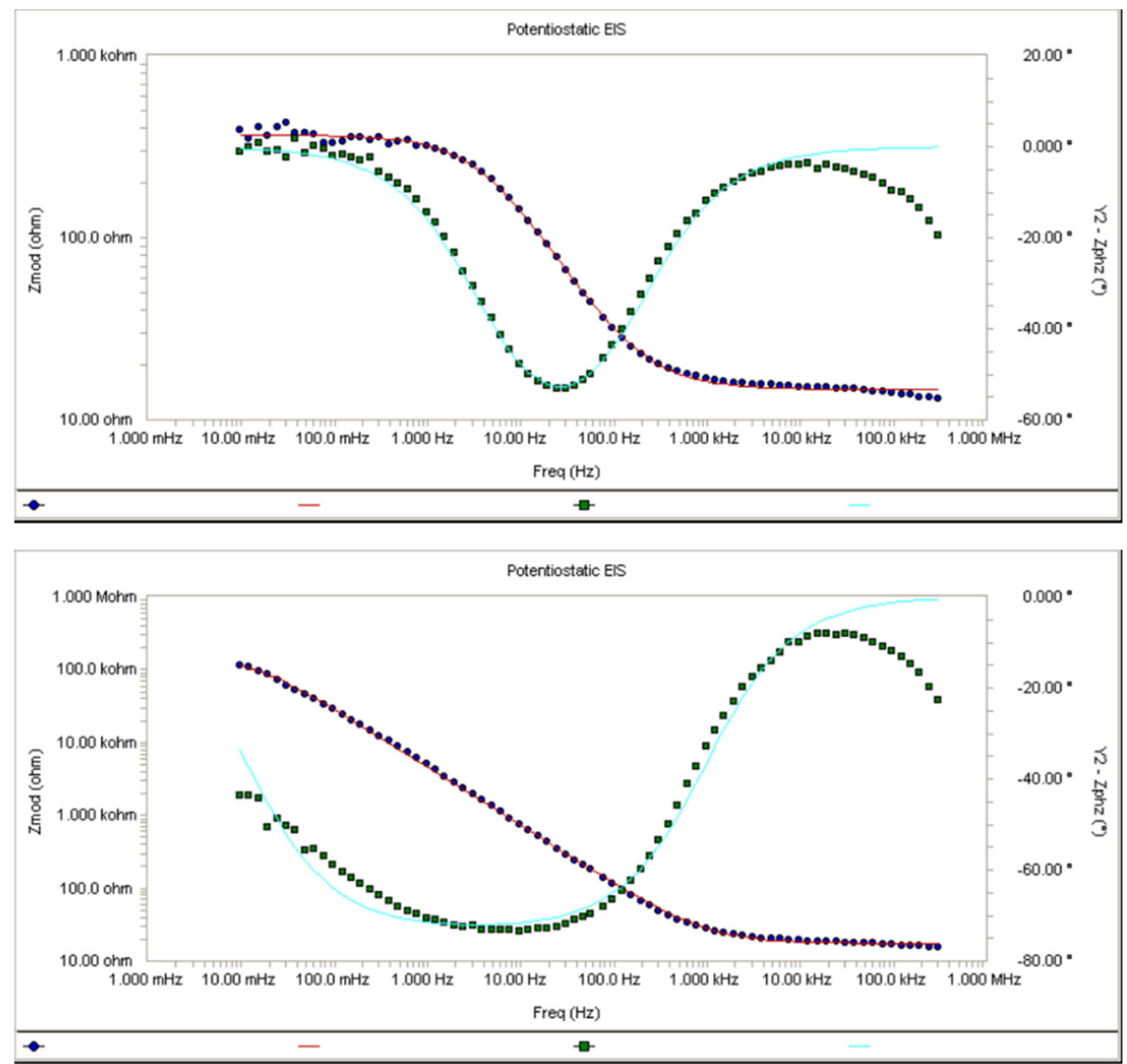

Fig. 10 Bode plot in $1 \mathrm{M} \mathrm{H}_{2} \mathrm{SO}_{4}$ without the inhibitor (top) and with inhibitor (bottom) 


$$
\Delta G_{\mathrm{ads}}=-2.303 R T \log \left(55.5 K_{\mathrm{ads}}\right) .
$$

The free energy of adsorption $\Delta G_{\text {ads }}$ for all cases (Table 1) had been negative and less than the threshold value of $-40 \mathrm{~kJ} / \mathrm{mol}$, and it confirms that the adsorption of inhibitors on steel is spontaneous and that physical adsorption mechanism is applicable.

\subsection{Electrochemical Impedance Study of the Inhibitors}

EIS study was carried out for better understanding of the fundamental aspect of electrochemical phenomena at metal-electrolyte interface. The phenomena at the interface of the metal surface and aqueous electrolyte is a complex process consisting of line of positive and negatively charged ions, capacitance due to electrical double layer, coating or film formation on surfaces, polarization resistance $\left(R_{\mathrm{p}}\right)$, pore resistance $\left(R_{\mathrm{po}}\right)$, and various impedances due to diffusion of ions, movement of charge in or away from metal surface and adsorption of cation and anion. The whole phenomena can be represented by an equivalent $\mathrm{AC}$ electrical circuit. The phenomena can be interpreted from Nyquist and Bode plots, which are depicted and discussed in the following sections. EIS has the great advantages over traditional DC electrochemical technique. The perturbation AC signal is very small, and the resultant polarization of the electrode is in a linear potential region. Therefore there is no destructive damage to the electrode. EIS technique is used to evaluate the time relation interface parameter (Table 2).

Figure 9 comparers Nyquist plots of steel in $1 \mathrm{~N} \mathrm{H}_{2} \mathrm{SO}_{4}$ without the inhibitor (top one) with addition of $1500 \mathrm{ppm}$ inhibitor (bottom one). It is seen with addition of the inhibitor, length of semi circle has increased(x-axis kohm scale and ohm scale) indicating increase in polarization resistance, giving rise to decrease in corrosion rate. The bode plots (Fig. 10) also show that impedance (y-axis) is more for the system with inhibitor at all frequencies. The maximum phase angle is close to 90 for system with the inhibitor, indicating a pure capacitive load of the impedance when the inhibitor was in the solution. This explains why and how the inhibitor functions in deceasing the corrosion rate.

\section{Conclusion}

A new green inhibitor, papaya seed, a vegetable waste, has come up, in inhibiting the acid corrosion of steel which has huge applications as containers as well as many bio applications. This inhibitor brings down the degradation rate of steel by several hundreds times without doing any harmful effects to the environment. The percentage of corrosion retardation depends on the concentration of acid as well as the amount of inhibitor added. The mechanism of corrosion inhibition is by physical adsorption on the metal surface at cathodic and anodic sites, thereby blocking the anodic and cathodic reactions. The present study opens up a new thought of investigating papaya seed extract in other bio and tribo applications.

\section{Compliance with ethical standards}

Conflict of interest The work was carried out with author own fund and there is second or third party involved.

\section{References}

1. Bentiss F, Traisnel M, Lagrenee M (2000) The substituted 1, 3, 4-oxadiazoles: a new class of corrosion inhibitors of mild steel in acidic media. Corros Sci 42:127

2. Schmitt G (1984) Applications of inhibitors for acid media: report prepared for the European federation of corrosion working party on inhibitors. Br Corros J 19:165

3. Raja PB, Sethuraman MG (2008) Natural products as corrosion inhibitor for metals in corrosive media-a review. Mater Lett 62:113

4. Arenas MA, Conde A, de Damborenea J (2002) Cerium: a suitable green corrosion inhibitor for tinplate. Corros Sci 44:511

5. El-Sawy MS, Abu-Ayana YM, Abdel-Mohdy FA (2001) Some chitin/chitosan derivatives for corrosion protection and waste water treatments. Anticorros Methods Mater 48:227

6. Cano E, Pinilla P, Polo JL, Bastidas JM (2003) Copper corrosion inhibition by fast green, fuchsin acid and basic compounds in citric acid solution. Mater Corros 54:222

7. Choi D-J, Kim Y-W, Kim J-G (2001) Development of a blended corrosion, scale, and microorganism inhibitor for open recirculating cooling systems. Mater Corros 52:697

8. Moretti G, Guidi F, Grion G (2004) Tryptamine as a green iron corrosion inhibitor in $0.5 \mathrm{M}$ deaerated sulphuric acid. Corros Sci 46:387

9. Raja PB, Sethuraman MG (2008) Natural products as corrosion inhibitor for metals in corrosive media-a review. Mater Lett 62:113

10. Paul S, Kar B (2012) Mitigation of mild steel corrosion in acid by green inhibitors: yeast, pepper, garlic and coffee. ISRN Corros 12:8. doi:10.5402/2012/641386

11. Odewunmi NA, Umoren SA, Gasem ZM (2014) Inhibition of mild steel corrosion in sulfuric acid solution using collagen. J Ind Eng Chem. doi:10.1016/j.jiec.2014.02.030

12. Paul S, Mandal C (2013) Biocompatibly coated steel as superior corrosion resistant implant material to $316 \mathrm{~L}$ steel. J Mater Eng Perform 22(10):3147-3154

13. Kermanshai R, McCarry BE, Rosenfeld J, Summers PS, Weretilnyk EA, Sorger GJ (2001) Benzyl isothiocyanate is the chief or sole anthelmintic in papaya seed extracts. Phytochemistry $57(3): 427-435$

14. https://www.classle.net/book/adsorption-and-adsorption-isotherms 